\title{
Application of TOPSIS Method using Entropy Weights to Compare Performance of Public Hotel Companies listed on the Stock Exchange of Thailand
}

\author{
Sunitiya Thuannadee \\ Suranaree University of Technology, Thailand
}

\begin{abstract}
Prior research on the performance of the hotel business in Thailand has been mostly conducted based on financial ratio analysis. Although financial ratio analysis has been widely used in measuring firms' performances, it cannot integrate multiple ratios simultaneously. Hence, this research aims to explore a multi-criteria decision-making tool called the Technique for Order of Preference by Similarity to Ideal Solution (TOPSIS) with Entropy weights to compare the financial performance of some hotel companies in Thailand. Moreover, ranking by TOPSIS was compared to the ranking by market value ratios which are price per earnings ratios (P/E ratios) and price per book value ratios (P/BV ratios) using Spearman's rank correlation 2-tailed test at 0.01 alpha level to investigate if there is any correlation between the rankings. Seven key financial ratios; the current ratio, the quick ratio, the gross profit margin, the net profit margin, the return on assets, the return on equity, and the debt per equity, were selected to be analyzed in this study. The author evaluated the 2018 financial ratios listed on the Stock Exchange of Thailand (SET). This study found that there was no significant correlation between the ranking by the TOPSIS method and the rankings by market value ratios.
\end{abstract}

Keywords: correlation; financial ratios; market value ratios; multi-criteria decision-making; Spearman's rank 